\title{
PENGEMBANGAN PENGGERAK SOLAR PANEL DUA SUMBU UNTUK MENINGKATKAN DAYA PADA SOLAR PANEL TIPE POLIKRISTAL
}

\author{
Oleh \\ Wendryanto ${ }^{1}$, G. Widayana ${ }^{2}$, W Sutaya ${ }^{3}$ \\ 1,2 Jurusan Pendidikan Teknik Mesin, Fakultas Teknik dan Kejuruan \\ Universitas Pendidikan Ganesha \\ ${ }^{3} J u r u s a n$ Pendidikan Teknik Elektro, Fakultas Teknik dan Kejuruan \\ Universitas Pendidikan Ganesha
E-mail : wendryanto@gmail.com¹,gedewidayana@gmail.com², sutaya.elkt@gmail.com ${ }^{3}$

\begin{abstract}
ABSTRAK
Prototipe ini didesain agar panel surya mampu senantiasa tegak lurus dengan matahari dengan menggunakan Arduino Nano 3.0 Atmega 328 CH340G sebagai control otomatis, serta komponen lain seperti sensor cahaya $(L D R)$ dan motor DC. Prinsip kerja dari mikrokontroler ini dalam penggerak panel surya 2 sumbu ini yaitu output dari sensor LDR diolah oleh mikrokontroler Arduino Nano 3.0 Atmega 328 CH340G dengan menggunakan bahasa pemrograman. Apabila sensor LDR tidak tegak lurus terhadap matahari, maka akan memiliki nilai tahanan yang berbeda. Jika terjadi perbedaan maka mikrokontroler akan merespon dan menggerakkan motor agar medapat nilai resistansi yang sama. Dari hasil pengujian dengan membandingkan panel surya yang statis, dengan pengerak 1 sumbu dan dengan penggerak 2 sumbu, didapat bahwa panel surya yang dilengkapi dengan penggerak 2 sumbu memiliki daya serap energi matahari yang lebih optimal. Hal ini dibuktikan dengan pengukuran tegangan listrik yang dihasilkan panel surya lebih besar apabila dibandingkan dengan panel surya yang statis maupun yang dengan penggerak 1 sumbu. Dari data yang didapat, terjadi peningkatan tegangan mulai pukul 09.00 dan tegangan maksimal yang didapat terjadi pada pukul 12.00, setelah itu terjadi penurunan tegangan yang dihasilkan.
\end{abstract}

Kata-kata kunci : Arduino Nano 3.0 Atmega 328ch340g, Motor DC, Penggerak Panel Surya 2 Sumbu.

\section{ABSTRACT}

This prototype is design for has be able to track the position of the sun with using an Arduino Nano 3.0 Atmega $328 \mathrm{CH} 340 \mathrm{G}$ for automatic control, with another component as well as LDR censor, and DC motor. The principle of this microcontroller in solar tracker dual axis is output of LDR censor processed by microcontroller Arduino Nano 3.0 ATmega $328 \mathrm{CH} 340 \mathrm{G}$ with assembly. If the LDR cencor not perpendicular with sun light, so cencor LDR have a deiferification the value of resistance. If that happens, so microcontroller will respond and move the DC motor to get the same value of resistance. Of the test result of compare static solar energy, solar tracker with one axis, and solar tracker with dual axis, be obtained that solar tracking with dual axis have a power to exploit of the sun light is more optimally. This can be proved with measuring of electrical voltage greater than static solar energy as well solar tracker with one axis. From the obtained of data, the increase of electrical voltage start from at 09.00 am and maksimum electrical voltage can be reach from $12.00 \mathrm{am}$, after that happen decline of electrical voltage.

Key Words: Arduino Nano ATmega 328 CH340G, DC Motor, Solar Tracker Dual Axis, 


\section{PENDAHULUAN}

Energi baru dan terbarukan mempunyai peran yang sangat penting dalam memenuhi kebutuhan energi. Hal ini disebabkan penggunaan bahan bakar untuk pembangkit-pembangkit listrik konvensional dalam jangka waktu yang panjang akan menguras sumber minyak bumi, gas dan batu bara yang semakin menipis dan juga dapat mengakibatkan pencemaran lingkungan.

Duniapun sudah mulai merubah tren produksi dan penggunaan bahan bakarnya, dari bahan bakar fosil beralih ke bahan bakar non-fosil, terutama tenaga surya yang tidak terbatas. Sistem Pembangkit Listrik Tenaga Surya (PLTS) akan lebih diminati karena dapat digunakan untuk keperluan apa saja dan di mana saja, bangunan besar, pabrik, perumahan, dan lainnya. Selain persediaannya tanpa batas, tenaga surya nyaris tanpa adanya polusi yang dihasilkan selama proses konversi energi dibandingkan bahan bakar lainnya. Di negara-negara industri maju seperti Jepang, Amerika Serikat dan beberapa negara di Eropa dengan bantuan subsidi dari pemerintah telah diluncurkan program-program untuk memasyarakatkan listrik tenaga surya ini. Tidak itu saja di negara-negara sedang berkembang juga mempromosikan pemakaian sumber energi yang dapat diperbaharui ini terus dilakukan (Halim,2012).

Sel surya merupakan salah satu devais untuk "memanen" energi matahari terbarukan yang terus dikembangkan. Penggunaan sel surya memiliki banyak keuntungan diantaranya: tidak membutuhkan bahan bakar fosil, polusi yang kecil dan biaya perawatan yang kecil. Karakteristik energi yang dihasilkan sel Surya sangat dipengaruhi oleh radiasi sinar matahari, temperatur, dan posisi sel surya terhadap sinar datang matahari. Sel surya akan menghasilkan energi maksimal pada saat posisi matahari tegak lurus terhadap permukaan sel surya. Posisi matahari akan selalu berubah dari timur ke barat setiap harinya, didukung dengan adanya gerak semu matahari. Perubahan posisi matahari tersebut akan mengakibatkan kecilnya energi yang dihasilkan oleh sel surya, sehingga dibutuhkan sebuah sistem yang dapat menggerakkan sel surya supaya bisa selalu tegak lurus terhadap sinar datang matahari.

Dalam proses konversi energi pada sel surya dipengaruhi banyak faktor yang dapat mengurangi optimalisasi pada proses konversi energi. Diantaranya adalah faktor orientasi terhadap matahari yang selalu berubah ubah dapat mengurangi optimalisasi sel surya dalam proses konversi energi matahari menjadi energi listrik. Sel surya akan menghasilkan daya maksimal ketika posisinya saling tegak lurus dengan cahaya matahari. (Karmon Sigalingging, 1994).

Sistem tracker surya merupakan suatu sistem yang bekerja mendeteksi posisi matahahari dengan menggunakan sensor cahaya dan mengontrol sel surya agar selalu tegak lurus terhadap matahari dengan mengubah arah timur-barat serta selatan-utara.

\section{TINJAUAN PUSTAKA}

\section{Panel Surya}

Sel surya atau juga sering disebut fotovoltaik adalah divais yang mampu mengkonversi langsung cahaya matahari menjadi listrik. Sel surya bisa disebut sebagai pemeran utama untuk memaksimalkan potensi sangat besar energi cahaya matahari yang sampai ke bumi, walaupun selain dipergunakan untuk menghasilkan listrik, energi dari matahari juga bisa dimaksimalkan energi panasnya melalui sistem solar thermal.

Secara sederhana, sebuah sistem pembangkit listrik tenaga matahari (solar electric system) terdiri dari lima bagian utama (Roberts, 1991) yaitu:

1. Modul sel surya (Photovoltaic module) : adalah bagian yang berfungsi untuk mengkonversikan energi matahari menjadi energy listrik.

2. Re-chargeable battery : adalah bagian yang berfungsi untuk menyimpan energi untuk digunakan pada saat malam hari dan selama waktu 
berawan (intensitas cahaya matahari kecil).

3. Kontrol unit : bagian yang berfungsi untuk menyeimbangkan beban yang sesuai dengan kemampuan sistem baik secara otomatis maupun secara manual, melindungi baterai dan kabel, memonitor performa dari sistem, dan memberikan peringatan bila terjadi sesuatu yang berjalan dengan tidak semestinya.

4. Saluran pendistribusian (Distributor) : bagian yang berfungsi untuk menyalurkan energi ke beban baik dalam DC ataupun AC.

\section{Sensor LDR}

Sensor LDR adalah sebuah komponen yang nilai resistansinya berubah karena adanya cahaya yang mengenai sensor tersebut. Dalam perancangan alat ini, terdapat 4 buah sensor LDR yang terbagi menjadi 2 posisi dan masing-masing posisi akan diberi dinding pembatas. Hal ini bertujuan agar masing-masing sensor akan memberikan sinyal kepada microkontroler secara jelas dan akurat.

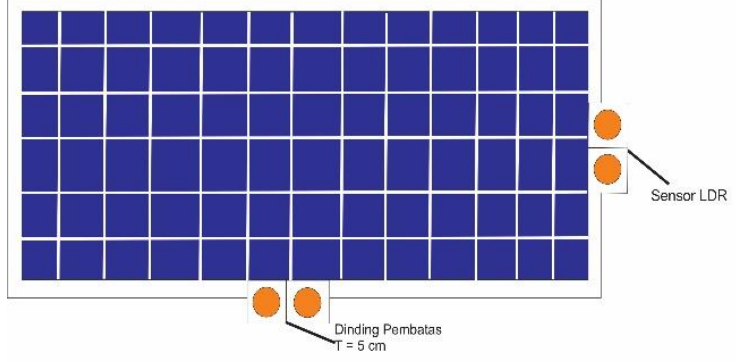

Gambar 1 . Letak Sensor LDR pada Panel Surya

\subsection{Aduino Nano ATmega 328}

Arduino adalah sebuah pengendali mikro board tunggal yang memiliki sifat terbuka (open source) yang diturunkan dari platform berbasis Wiring. Pengendali ini dirancang untuk mempermudah penggunaan dalam berbagai bidang elektronik. Hardware arduino mengandung prosesor jenis Atmel AVR, dan memiliki bahasa pemrograman tersendiri.

Arduino Nano adalah papan pengembangan (development board) mikrokontroler yang berbasis chip ATmega328P dengan bentuk yang sangat kecil. Secara fungsi tidak ada bedanya dengan Arduino Uno. Perbedaan utama terletak pada ketiadaan jack power DC dan penggunaan konektor Mini-B USB.

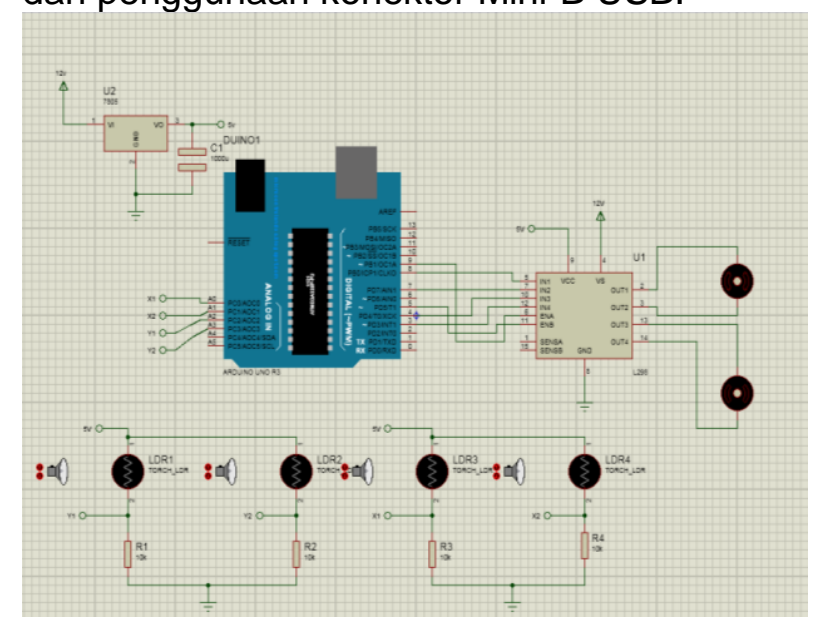

Gambar 2. Desain Rangkaian Arduino nano ATmega 328

Disebut sebagai papan pengembangan karena board ini memang berfungsi sebagai arena prototyping sirkuit mikrokontroller. Dengan menggunakan papan pengembangan, anda akan lebih mudah merangkai rangkaian elektronika mikrokontroller dibanding jika anda memulai merakit ATMega328 dari awal bread board.

Prinsip kerja dari Arduino dalam perancangan penggerak panel surya 2 sumbu yaitu, output dari sensor LDR diolah oleh Arduino ATmega328 dengan menggunakan bahasa pemrograman. Apabila sensor LDR tidak tegak lurus terhadap matahari, maka akan memiliki nilai tahanan yang berbeda. Jika terjadi perbedaan maka mikrokontroler akan merespon dan menggerakkan motor agar medapat nilai resistansi yang sama.

Flowchart prototype penggerak panel surya akan disaikan pada gambar 1. Ada dua proses yang terjadi dalam sistem tersebut, yaitu tracking (penjejakan sinar matahari) dan pengisian energi listrik ke dalam baterai. Komponen utama penyusun sistem ini adalah sensor LDR, mikrokontroler Arduino Nano ATmega 328, panel surya, dan baterai.

Prinsip kerja dari Arduino dalam perancangan penggerak panel surya 2 sumbu yaitu, output dari sensor LDR diolah oleh Arduino ATmega328 dengan menggunakan bahasa pemrograman. Apabila sensor LDR tidak tegak lurus 
terhadap matahari, maka akan memiliki nilai tahanan yang berbeda. Jika terjadi perbedaan maka mikrokontroler akan merespon dan menggerakkan motor agar medapat nilai resistansi yang sama.

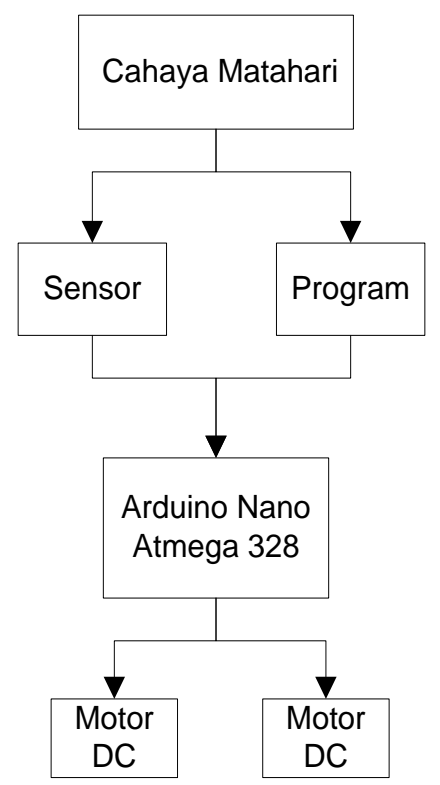

Gambar 3. Flowchart cara kerja alat

\section{Motor DC}

Motor DC merupakan actuator dari system pengendalian solar tracker yang akan menggerakkan photovoltaic sesuai dengan arah matahari. Penjejak matahari memanfaatkan polaritas dari motor DC. Dimana, apabila menginginkan polaritas kekanan, maka diberikan tegangan positif, sedangkan apabila menginginkan polaritas kekiri, maka diberikan tegangan negative atau sebaliknya.

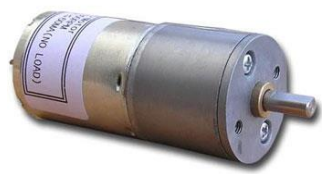

Gambar 4. Motor DC

\section{Metode Penelitian}

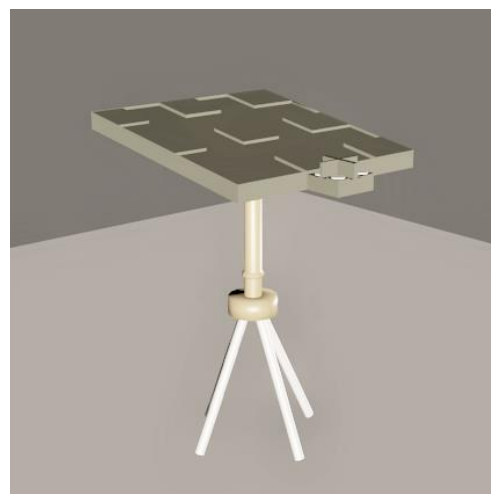

Gambar 5. Desain Penggerak Panel Surya

\section{Pengujian Motor}

Pengujian motor dan Arduino dapat disatukan karena motor digunakan sebagai indicator kerja mikrokontroler. Mikrokontroler akan diberikan program untuk menjalankan motor dan pin pada mikrokontroler akan dihubungkan pada motor. Jika motor berjalan sesuai program maka motor dinyatakan dalam kondisi baik. Begitu juga mikrokontroler dinyatakan

dalam kondisi baik karena dapat menerima dan membaca program.

\section{Pengujian Sensor}

Pengujian sensor dilakukan untuk mengidentifikasi apakah sensor berjalan dengan baik, yaitu dengan menghubungkan sensor dengan port $A$ pada mikrokontroler. Karena pada portA terdapat ADC sehingga nilai dari sensor dapat langsung dibaca oleh mikrokontroler

\section{Pengujian Alat Secara Keseluruhan}

Sebelum melakukan pengujian alat dilapangan, alat penggerak panel surya terlebih dahulu di uji kelayakan. Hal ini bertujuan agar dapat meminimalisir kesalahan pada saat melakukan pengujian tegangan yang dihasilkan. Alat terlebih dahulu di uji dengan meberikan sumber cahaya yang diarahkan kepada semua sensor LDR. Jika alat dapat bekerja dengan baik, maka panel surya tersebut dapat memposisikan sesuai dengan arah datangnya sumber cahaya. Dalam pengembangan produk ini, berikut merupakan diagram alir dalam perakitan 
prototype penggerak panel surya 2 sumbu,

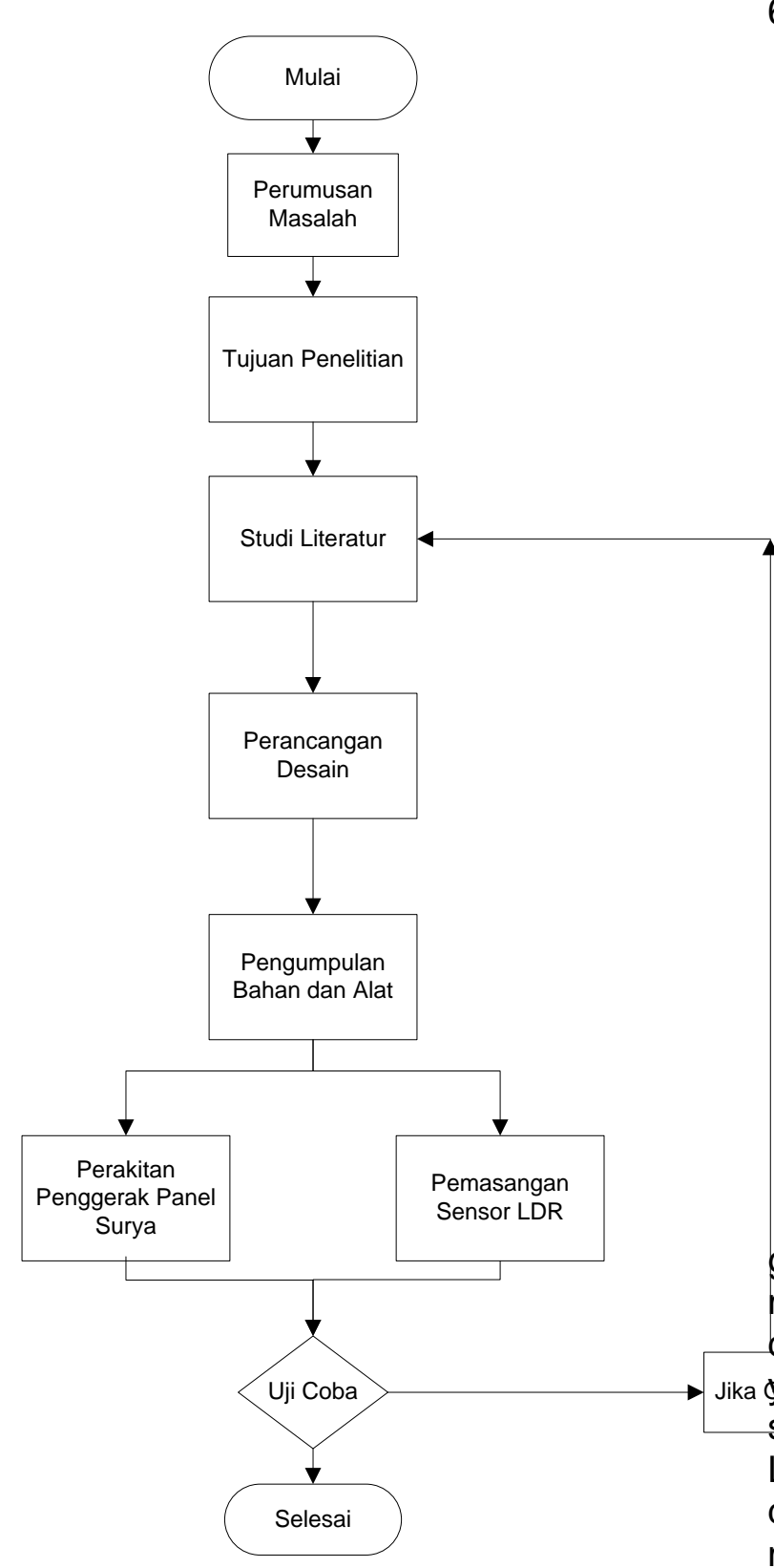

Gambar 6. Flowchart Perakitan Prototipe

\section{Tahapan Penelitian}

Tahapan yang dilakukan dalam pengujian adalah sebagai berikut:

1. Letakan solar panel menghadap ke arah langit,

2. Pasang multimeter ke bateray dan panel surya yang akan di ukur,

3. Ukur setiap 1 jam,

4. Catat hasil pengukuran tersebut sesuai dengan yang dihasilkan,
5. Ulangi langkah 1-4 untuk hari berikutnya selama 3 hari,

6. Buat tabel variasi tegangan baterai terhadap waktu.

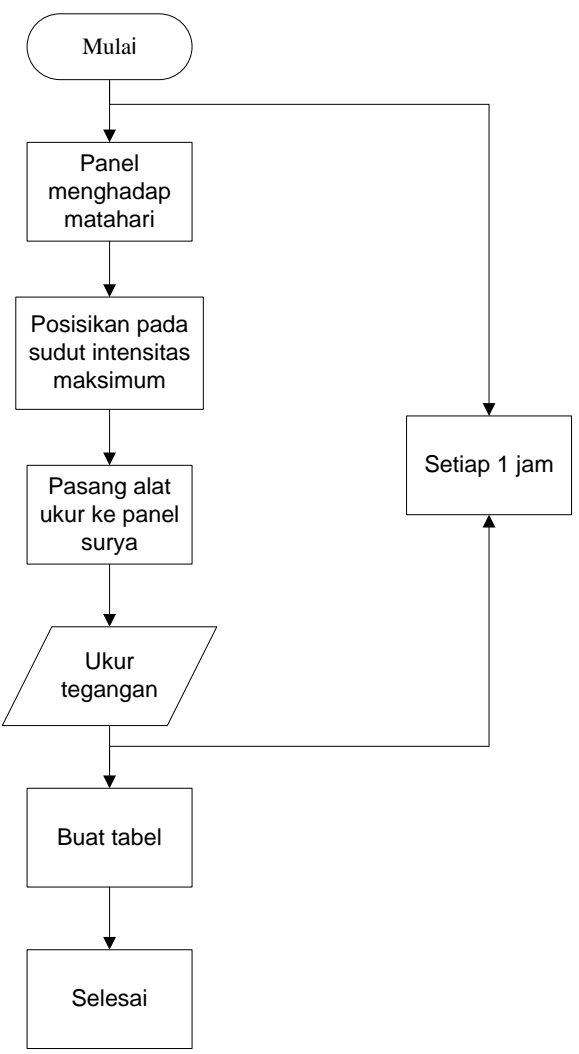

Gambar 7. Flowchart Penelitian

Realisasi alat diperlihatkan pada gambar 5. Bagian paling atas dari gambar memperlihatkan panel sel surya yang dapat berputar karena adanya motor DC Jika grayg digerakkan oleh driver motor DC. Di sebelah kiri gambar menunjukkan sensor LDR yang berfungsi mendeteksi arah datangnya cahaya matahari sehingga bisa menentukan perputaran sel surya. Dibawah panel surya terdapat mikrokontroler dan driver motor.

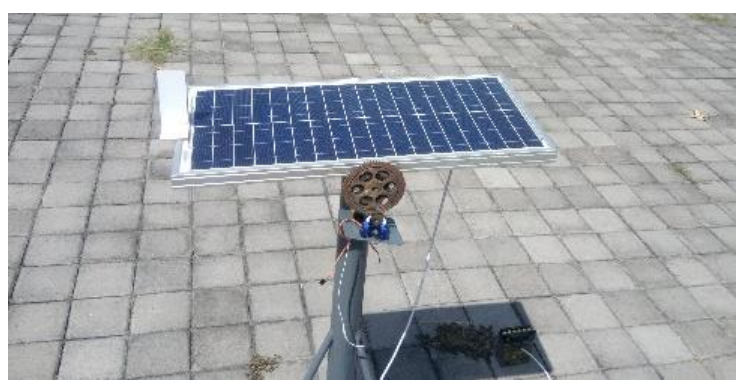

Gambar 8. Prototipe Alat 


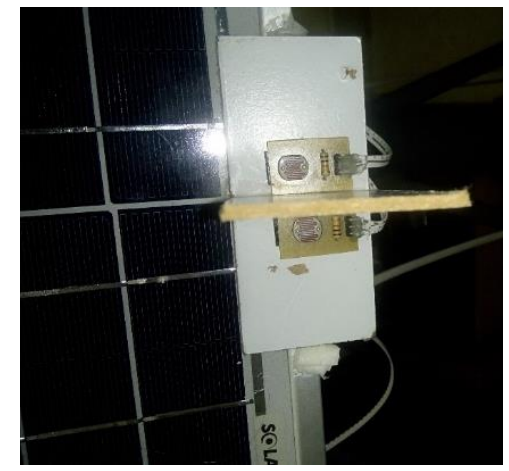

Gambar 9. Sensor LDR untuk sumbu

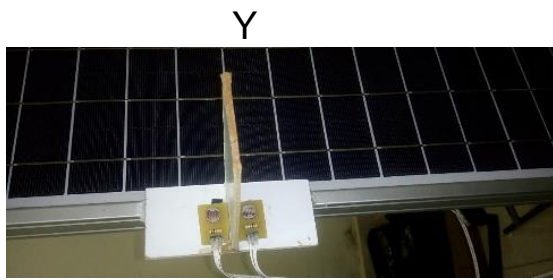

Gambar 10. Sensor LDR untuk sumbu $X$

Dalam uji lapangan, prototipe akan diletakkan di lapangan terbuka selama 8 jam (pukul 08.00-16.00). Kemudian, setiap 1 jam akan dilakukan pengukuan tegangan dengan menggunakan multimeter pada panel surya serta baterai. Hasil pengujian dapat dilihat pada tabel 1 .

\begin{tabular}{|c|c|c|c|}
\hline Waktu & keterangan & $\begin{array}{c}\mathrm{V} \\
\text { Baterai }\end{array}$ & $\begin{array}{c}\mathrm{V} \\
\text { Panel } \\
\text { Surya }\end{array}$ \\
\hline 08.00 & 1 jam & 10 & 19.50 \\
\hline 09.00 & 1 jam & 10.3 & 19.70 \\
\hline 10.00 & 1 jam & 10.5 & 20 \\
\hline 11.00 & 1 jam & 10.8 & 20.43 \\
\hline 12.00 & 1 jam & 11 & 20.80 \\
\hline 13.00 & 1 jam & 11.5 & 21.00 \\
\hline 14.00 & 1 jam & 12 & 20.80 \\
\hline 15.00 & 1 jam & 12 & 20.30 \\
\hline 16.00 & 1 jam & 12 & 19.50 \\
\hline
\end{tabular}

Tabel 1. Hasil Pengujian
Pada pengukuran hari pertama dengan penggerak panel surya ini, kurva grafik pengukuran tegangan pada baterai menunjukan garis voltase mulai meningkat dari pertama diletakan di lokasi pengukuran dengan tegangan $10 \mathrm{~V}$ pada pukul 08.00 tegangan pada baterai ini terus mengalami peningkatan di setiap jamnya sampai akhir pengukuran pada pukul 16.00 mendapat tegangan pada baterai sebesar 12V. Begitu pula pada tegangan panel surya, kurva grafik panel surya menunjukan garis tegangan mulai meningkat dari pukul 09.00 dengan tegangan sebesar $19.53 \mathrm{~V}$, tegangan ini terus mengalami peningkatan sampai tegangan puncak terjadi pada pukul 12.00 sampai 14.00 dengan tegangan sebesar $21 \mathrm{~V}$, setelah itu tegangan mulai perlahan mengalami penurun.

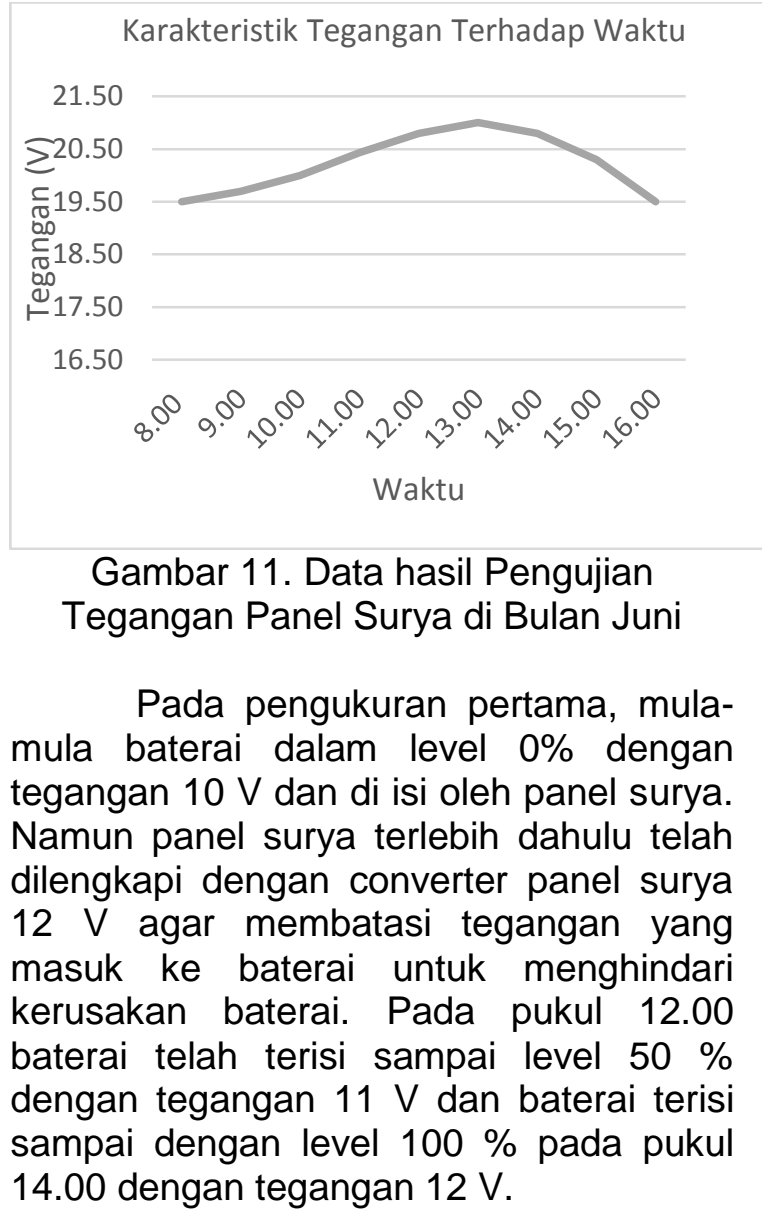




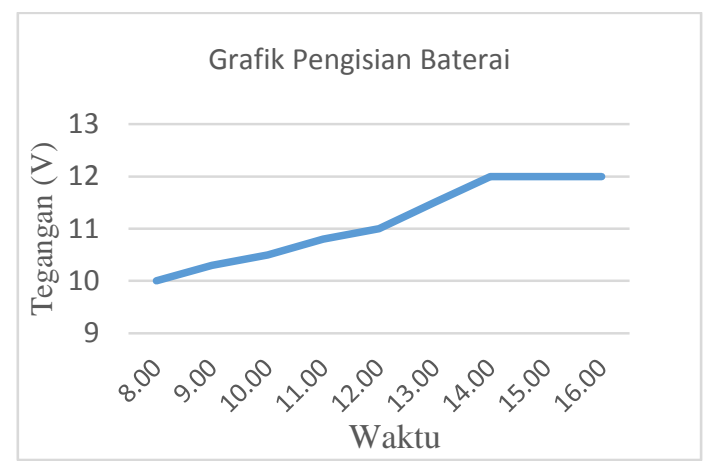

Gambar 12. Data hasil Pengujian

Tegangan Baterai di Bulan Juni

Berikut ini merupakan hasil perbedaan tegangan yang dihasilkan panel surya statis dan dengan penggerak 1 sumbu maupun dengan penggerak 2 sumbu.

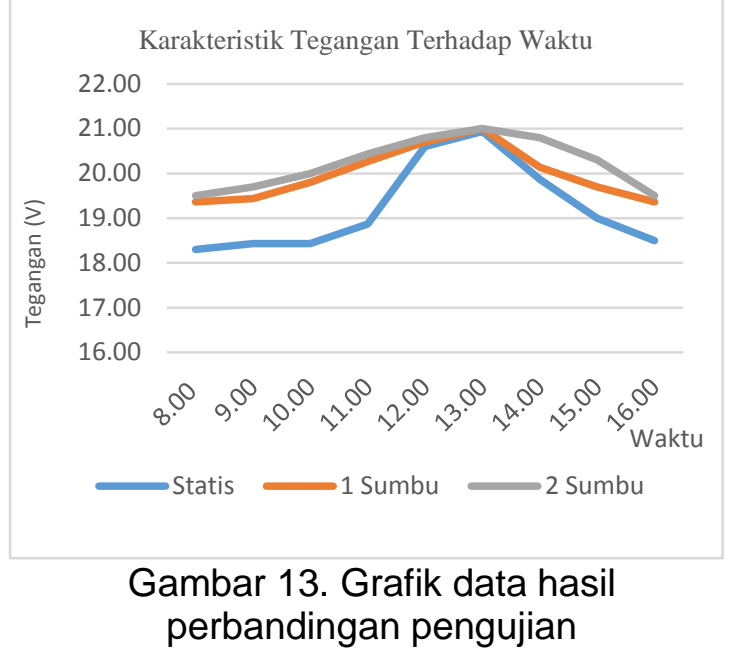

Berdasarkan grafik hasil perbandingan pada gambar 4.3 pengaruh perbandingan tegangan yang dihasilkan panel surya yang dilengkapi dengan penggerak 2 sumbu. Efek dari penggerak panel surya ini dapat dilihat pada tabel serta grafik yang terdapat pada setiap pengujian. Pada panel surya statis, tegangan yang dihasilkan mendekati sama dengan panel surya yang menggunakan penggerak di antara pukul 12.00-13.00 dan pada jam berikutnya terliat mulai menurun.

Pengaruh penggerak dengan control otomatis atau yang sering disebut dengan Solar Tracker memang mampu membantu proses penyerapan energy matahari dengan lebih optimal dibandingkan dengan yang tanpa penggerak maupun yang dengan 1 sumbu. Hal ini dapat dibuktikan pada grafik 4.7 yang menunjukkan perbandingan penyerapan energy matahari melalui panel surya yang statis, dengan penggerak 1 sumbu (X) dan dengan penggerak 2 sumbu ( $X$ dan $Y$ ). Tegangan maksimum yang dihasilkan panel surya terjadi pada sekitar pukul 12.00-13.00, dan tegangan minimum terjadi pada pukul 16.00 .

Tegangan adalah perbedaan potensial listrik antara dua titik dalam rangkaian listrik, dan dinyatakan dalam satuan volt. Besaran ini mengukur energi potensial dari sebuah medan listrik yang mengakibatkan adanya aliran listrik dalam sebuah konduktor listrik. Efek panel surya yang dilengkapi dengan penggerak atau Solar Tracker terbukti mampu memanen energy matahari dengan efisien dibandingkan dengan panel surya statis.

Pada pengujian Solar Tracker, tidak mendapat hasil yang begitu signifikan antara panel surya dengan penggerak 1 sumbu dengan penggerak 2 sumbu. Hal ini dikarenakan karena pada penelitian sebelumnya, Solar Tracker 1 sumbu juga pengujiannya tepat pada bulan Juni seperti yang peneliti lakukan saat ini. Akan teapi tentu hasilnya akan lebih berbeda pada saat pegujiannya dilakukan di bulan lain, karena seperti yang kita ketahui bahwa bumi mengalami revolusi sehingga sudut kemiringannya pun ikut berubah-ubah selama 1 tahun.

\section{Kesimpulan}

Tegangan awal yang didapat dari panel surya statis yaitu $18,30 \mathrm{~V}$ dan semakin menigkat pada tiap jam, dan tegangan maksimal yang didapat dari panel surya statis terjadi pada pukul 13.00 dengn tegangan 20,93 V. setelah bberap jam berikutnya perlahan tegangan yang dihasilkan mulai menurun.

1. Tegangan awal yang didapat dari panel surya dengan penggerak 1 sumbu yaitu $19,37 \mathrm{~V}$ dan semakin menigkat pada tiap jam, dan tegangan maksimal yang 
didapat dari panel surya statis terjadi pada pukul 13.00 dengn tegangan 21V. setelah bberap jam berikutnya perlahan tegangan yang dihasilkan mulai menurun.

2. Tegangan awal yang didapat dari panel surya dengan penggerak 2 sumbu yaitu $19,50 \mathrm{~V}$ dan semakin menigkat pada tiap jam, dan tegangan maksimal yang didapat dari panel surya statis terjadi pada pukul 13.00 dengn tegangan 21 V. setelah bberap jam berikutnya perlahan tegangan yang dihasilkan mulai menurun.

3. Panel surya yang dilengkapi dengan penggerak (Solar Tracker) terutama yang memiliki 2 sumbu terbukti lebih efektif dalam proses penyerapan energy matahari karena panel surya dapat mengikuti arah pergerakan matahari dengan baik selama sehari.

\section{Saran dan Harapan}

Adapun saran yang penulis dapat sampaikan sehubungan dengan pengembangan penggerak solar panel dua sumbu untuk meningkatkan daya pada solar panel tipe polikristal ini yaitu:

1. Agar masyarakat mengetahui kebermanfaatan dari penggerak panel surya 2 sumbu dalam upaya meningkatkan daya pada solar panel.

2. Agar masyarakat lebih ikut mengambil bagian dari perkembangan energi terbarukan dengan lebih baik lagi.

3. Perlu dilakukan pengembangan penggera panel surya lebih lanjut dengan mekanik penggerak serta perhitungan torsi yang lebih baik lagi.

4. Selain itu harapan terbesar dari penulis dalam penelitian ini, semoga sebagian atau seluruh isi dari skripsi ini dapat bermanfaat dan berguna bagi penulis, lembaga, mahasiswa PTM Undiksha, maupun masyarakat lainnya.

\section{UCAPAN TERIMA KASIH}

Terima kasih kepada Tuhan YME, karena atas berkat dan rahmat-Nya penelitian dan penulisan artikel ini telah selesai tepat pada waktunya. Tidak lupa juga kami mengucapkan terima kasih kepada beberapa pihak yang juga ytelah membantu peneliti dalam menyelesaikan penelitian ini. Untuk itu peneliti ingin mengucapkan terima kasih kepada:

1. Dr. Kadek Rihendra, S.T., M.T selaku Ketua Jurusan Pendidikan Teknik mesin yang telah memberikan arahan, saran, serta motivasi dalam penelitian ini.

2. I Gede Widayana, S.T., M.T selaku Dosen Pembimbing yang telah memberikan bimbingan, arahan, saran, serta motivasi dalam penelitian ini.

3. I Wayan Sutaya, S.T., M.T selaku Dosen Pembimbing yang telah memberikan bimbingan, arahan, saran, serta motivasi dalam penelitian ini.

4. Orang tua dan seluruh keluarga yang selalu memberikan dukungan dalam bentuk dana, motivasi serta moril.

5. Rekan-rekan Mahasiswa Pendidikan Teknik Mesin.

\section{Daftar Rujukan}

Alamendah. (2016, October 8). Alamendah's Blog. Diakses dari http://alamendah.org

Departemen Energi dan Sumber Daya Mineral. 2010. Pemanfaatan Energi Surya Di Indonesia.

Hardianto, H. E., \& Rinaldi, R. S. (2012). Perancangan Prototype Penjejak Cahaya Matahari Pada Aplikasi Pembangkit Listrik Tenaga Surya. Jurnal IImiah Foristek, 208.

Hardianto, H. E., \& Rinaldi, R. S. (2012). Perancangan Prototipe Penjejak Cahaya Matahari Pada Aplikasi Pembangkit Listrik tenaga Surya. Jurnal IImiah Foristek, 209.

Pambudi, S. (2012, February 24). sir.stikom.edu. Diakses dari Pengertian Sensor LDR: http://sir.stikom.edu/167/6/BAB $\% 2011$. .pdf

Robert, Simon. 1996. Solar Elctricity, A Partial Guide to Designing and Installing Small Photovoltaic System. Prentice Hill. New York. 
Sandos Simatupang, B. S. (2013).

Rancang Bangun dan Uji Coba

Solar Tracker pada Panel Surya

Berbasis Mikrokontroller

ATmega16. Jurnal Keteknikan

Pertanian Tropis dan Biosistem,

57.

Soenadi, A. (2015, Maret 2). Mengenal Panel Surya. Diakses dari https://nofisi.blogspot.co.id

Universitas Negeri Semarang. (2010, July 17). Tentang Arduino Nano ATMega328. Retrieved from uns.ac.id.

http://npx21.blog.uns.ac.id/2010/

07/17/atmega328/ 